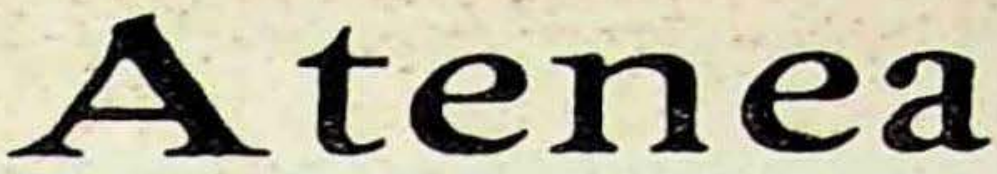

Revista publicada por la Universidad de Concepción COMISION DIRECTORA:

Enrique Molina, Samuel Zenteno A., Luis D. Cruz Ocampo, Salvador Gálvez y Abraham Valenzuela C. (Secretario).

Editor y Agente General: CARLOS JORGE NASCIMENTO AÑO II MARZO 31 DE 1925

NÚM. 1

Enrique Molina

\title{
¿Ha sonado la hora de la espada?
}

Al señor Leopoldo Lugones.

㩊 $\mathrm{L}$ poeta, el verdadero poeta es el vidente. es el privilegiado del espíritu para traducir en verbo humano lo que avizora en vuelos suprasensibles y de dificil acceso al común de los mortales: es el por tador de las cuerdas divinas que vibran con el dolor de los demás. Los demás se encuentran expresados en él y se dicen: esto es lo que he sentido, esto es lo que siento, y le agradecen al poela la iluminación de esperanza producida. el alivio al pesar traido con su ahondar en las complejidades del corazón. El poeta es el creador de belleza. es el pontifice del amor en todas sus formas. Vuela por esto en planos superiores a las miserias ordinarias de la vida o les aplica el cauterio de su fuego de profeta indignado cuando provienen de la mezquindad y maldad de los hombres. Es asi antena 
de luz que grita a los extraviados y abatidos morlales cavanzad. avanzad, realicemos con valor la vida, hagamos a Dios..

Un poela, el poeta argentino Leopoldo Lugones ha dicho en un leatro de Lima, en una de las festividades celebradas con motivo del centenario de la batalla de Ayacucho. que tha sonado para bien dei mundo la hora de la espada. Como corolario de esla frase de aparalosa marcialidad, ha agregado que eel pacifismo no es más que el cullo del miedo o la añagaza de la conquista roja, y que en el conflicto de la ley. cada ve\% más frecuente. porque es un desenlace. el hombre de espada liene que estar con ellas.

Creemos que en este discurso el señor Lugones no ha estado a la altura ni del poeta. ni del hombre público conductor de pueblos. ni del historiador.

Decir que sha sonado para bien del mundo la hora de la espada, es dar a entender que la humanidad hubiera vivido hasta estos dias en una paz enervante $y$ desmoralizadora. Pero. ¿no ha sido al contrario. la verdad que las horas de los pueblos han sido casi siempre horas de la espada? No tenemos para qué referirnos nada más que a la Europa y a la América. El viejo continente ha vivido los últimos cien años o en guerra - en paz armada que es. en forma negativa. también el imperio abrumador de la espada. Ha vivido asi hasta llegar a la catástrofe espantosa de 1914-1918. Más de diez millones de muerlos en los campos de balalla. un número mayor aún de mujeres. de niños y de civiles fenecidos por consecucncias indireclas de la guerra. como ser. falta de alimentación y enfermedades. centenares de pueblos destruidos. campos arrasados. epidemias que han dado la vuelta al mundo como azoles de un castigo universal: eslo ha caido sobre la infeliz humanidad por haber sonado. de modo más intenso que antes. en 1914 la hora de la espada. Aun no se aquietan las ondas de zozobras levantadas en esas horas falidicas, y muchos decenios pasarán 
¿Ha sonado la hora de la espada?

antes que se aquieten por completo, por si solas. si es que no estalla antes otra conflagración conforme a lo que parece descar la insana actitud bélica del señor Lugones.

¿No ha pensado el señor Lugones en este calaclismo? ¿Cómo creerlo? ¿O le parecen muy largos los cinco años de defectuosisima paz que van transcurridos desde 1919 hasta este momento?

Por si el cuadro anterior no fuera bastante. desentrañemos lo que pueda significar el imperio de la espada.

Es sagrado el empleo que hacen de las armas los pueblos que luchan por su independencia o las colectividades que defienden sus derechos hollados. Nobles fueron asi las espadas de Ayacucho y de Maipú. Y dada nuestra imperlecta organización internacional. también es cierto que los estados han tenido hasta hoy que mantenerse armados para asegurar su existencia: pero en estos casos el ejercicio de las armas significa y debe significar una función subalterna dentro de la organización civil. Fuera de estos capitulos, el imperio de la espada envuelve sólo el predominio de la fuerza bruta.

¿Le ha atribuido el señor Lugones tal vez a la espada una virlud organizadora? iAh. no!

Ella carece de esa virtud y puede sólo establecer un orden aparente. Toda unión de los hombres que no descansa en la voluntad y adhesión espontánea de los asociados. constituye una falsa organización, una apariencia de orden. El predominio de las armas connota el uso de instrumentos que únicamente sirven para atemorizar y tiranizar a los hombres. para herir y matar. es decir. para envilecer y prostituir la vida o para destruirla.

El pacifismo que el poeta argentino en su postura de Bayar do o Campeador teatral llama .culto del miedo. no es más que el clamor del buen criterio humano señalando la posibilidad de que los hombres sean capaces de vivir algún dia sin estúpidas querellas. Es tan antiguo como la razón humana y, lejos de 
ser el culto del miedo. entraña la exaltación del valor del espiritu que quiere realizarsc integramente: es la conclusión necesaria de toda verdadera moral. de toda religión. de todo evangelio de amor.

Las tragedias, al parecer incurables, de la Europa. han hecho pensar en la América como en una tierra de promisión donde puede florecer una nueva humanidad que alcance a realizar un ideal de perfección, imposible para el Viejo Mundo precisamente por llevar en su seno la fuerza disolvente de complicaciones $y$ odios engendrados por guerras seculares.

Bolivar. el rayo de la guerra. Tué en cierto sentido el primer pacifista hispano-americano. porque soñaba con que los pueblos de este continente se agruparan en una unión que fuera para ellos fuente de paz y grandeza.

En nuestros dias la élite del pueblo mejicano. llevando como más elocuente vocero a Vasconcelos. es pacifista. Y no se podrá decir de ellos que rinden culto al miedo. Rinden culto de amor. según sus propias declaraciones, al progreso. a la humanidad y especialmente a las naciones latino-americanas.

A las orillas del Plata se ha dejado oir recientemente la palabra cálida del Decano de la Facultad de Derecho señor Alfredo L. Palacios. Se dirige a los uriversitarios hispano-americanos para que nos apartemos de los nefastos ejemplos europeos y abramos en nuestro continente nuevos horizontes a la humanidad.

La cultura europea. dice, amenaza desencadenar una guerra interminable, capaz de hundir en el caos la civilización de Occidente: ¿Seguiremos nosotros, pueblos jóvenes. esa curva descendente? ¿Seremos tan insensatos que emprendamos a sabiendas un camino de disolución? ¿Nos dejaremos vencer por los apetitos y codicias materiales que han arrastrado a la destrucción a los pueblos europeos? Y luego invila a trabajar por la solidaridad espiritual de las naciones de la América Latina.

La revista AAtenea., de la Universidad de Concepción de.Chile. ha venido consagrando en todos sus números páginas al fo. mento de la confraternidad hispano-americana. 
Contra estas tendencias se ha alzado el señor Lugones en un teatro limeño. El poeta argentino ha creido que ha sonado la hora de la espada y lo celebra. La espada asi presentada no significa sino dos formas de calamidades: o la guerra exterior. - el régimen de fuerza, la tiranía en el interior.

Y para que no hubiera la menor duda de que esto era lo que queria decir. el señor Lugones endereza en seguida su discurso a ensalzar. en presencia del Dictador. la dictadura. ¿Pacilismo. bolcheviquismo. democracia, ha dicho, son sinónimos de las mismas vacantes que el destino ofrece al jefe predestinado. es decir. al hombre que manda por su derecho de mejor. con o sin la ley. porque ésta. como expresión de potencia. se confunde con su voluntad.

¡Qué impudicia, qué descenso!

Podemos convenir en que los gobiernos democráticos y parlamentarios hayan fracasado en muchas partes: pero debemos buscar sin histerismos peligrosos los remedios a los males politicos y sociales. en las virtualidades de la misma democracia constitucional.

Las loas a la guerra del señor Lugones, incomprensibles de todas maneras en un intelectual de alta cultura. se explicarian hasta cierto punto, como un producto de las circunstancias. El poeta ha vivido dias de grandes festividades y ha hablado en un teatro caldeado con las emociones de esas horas de exaltación patriótica y palaciega. Serian un gesto de marcialidad sin peligro, marcialidad escénica y conquistadora de fáciles aplausos. Pero legitimar y ensalzar la dictadura, arrojar flores a la planta del dictador ahi mismo donde han sido masacrados estudiantes y obreros porque han protestado de la farsa politica de querer consagrar la república al Sagrado Corazón, es demasiado.

El señor Lugones ha traicionado su investidura de pocta y de obrero de la espiritualidad hispano-americana.

Universidad de Concepción (Chile) Enero-1925. 